\title{
Correction to: Cranial MR-guided Focused Ultrasound for Essential Tremor
}

\section{Technical Considerations and Image Guidance}

\section{J. Levi Chazen ${ }^{\text {· Travis Stradford }}$ • Michael G. Kaplitt ${ }^{2}$}

Published online: 14 December 2018

○) Springer-Verlag GmbH Germany, part of Springer Nature 2018

\section{Correction to:}

\section{Clin Neuroradiol 2018}

https://doi.org/10.1007/s00062-018-0709-x

The original version of this article unfortunately contained a mistake. The tagging of the name J. Levi Chazen was incorrect. The correct information is given here.

The online version of the original article can be found under https://doi.org/10.1007/s00062-018-0709-x.

\footnotetext{
J. Levi Chazen

jlc2008@med.cornell.edu

Travis Stradford trs7005@nyp.org

Michael G. Kaplitt mik2002@med.cornell.edu

1 Department of Radiology, Weill Cornell Medicine, New York-Presbyterian Hospital, 525 East 68th Street, New York, NY 10065, USA

2 Department of Neurosurgery, Weill Cornell Medicine, New York-Presbyterian Hospital, 525 East 68th Street, New York, NY 10065, USA
} 